\title{
Ensino em tempos de pandemia: um novo cenário, com (não tão) novas necessidades
}

Teaching in pandemic times: a new scenario, with (not so) new necessities

\author{
Enseñar em tiempos de pandemia: um nuevo escenario, com (non tan) nuevas \\ necesidades
}

\author{
Leila Miyuki Saito ${ }^{1}$ \\ Marcelo Cristiano Acri ${ }^{2}$
}

\section{Resumo}

A pandemia do Covid-19 ocasionou diversas mudanças no cenário educacional: a suspensão das aulas presenciais e a adoção do ensino remoto emergencial puseram à prova a capacidade de adaptação ao novo contexto e trouxeram à tona discussões importantes acerca da formação (inicial e continuada) de professores. A título de ilustração, a pesquisa "Educação escolar em tempos de pandemia" (FUNDAÇÃO CARLOS CHAGAS, 2020) mostra que o letramento digital e o letramento em avaliação constituem conhecimentos que já se faziam imprescindíveis mesmo em tempos de ensino presencial, e que poderiam ter auxiliado amenizando a transição para o ensino remoto emergencial. Nesse sentido, este artigo visa a estabelecer diálogo entre os pressupostos do letramento digital (DUDENEY et al., 2016; HEALEY et al., 2008) e do letramento em avaliação (QUEVEDO-CAMARGO; SCARAMUCCI, 2018; STIGGINS, 1991) combinados às metodologias ativas (BACICH, 2017; DIEHL, 2020; MITRE et al., 2008; RESER; ROCHA; SILVA, 2018) no atendimento às demandas geradas no contexto de ensino remoto durante e pós-pandemia.

Palavras-chave: Ensino remoto emergencial; formação de professores; letramento digital; letramento em avaliação; metodologias ativas.

\begin{abstract}
The Covid-19 pandemic brought several changes to the educational scenario: the suspension of on-site classes and the adoption of emergency remote teaching tested the ability to adapt to the new context and brought to light important discussions about (initial and continuing) teacher training. To illustrate this point, the research "School education in times of pandemic" (FUNDAÇÃO CARLOS CHAGAS, 2020) shows that digital literacy and assessment literacy constitute knowledge that was already essential even in times of face-to-face teaching, and that could have helped in making a smoother transition to emergency remote teaching. In this sense, this article aims at establishing a dialogue between the assumptions of digital literacy (DUDENEY et al., 2016; HEALEY et al., 2008) and assessment literacy (QUEVEDOCAMARGO; SCARAMUCCI, 2018; STIGGINS, 1991) combined to active methodologies (BACICH, 2017; DIEHL, 2020; MITRE et al., 2008; RESER; ROCHA; SILVA, 2018) in

\footnotetext{
${ }^{1}$ Mestra pelo Programa de Mestrado Profissional em Letras Estrangeiras Modernas - MEPLEM, pela Universidade Estadual de Londrina (2018). Doutoranda em Estudos da Linguagem, pela Universidade Estadual de Londrina. Email: saito.leila@gmail.com. ORCID: https://orcid.org/0000-0003-0594-6906

${ }^{2}$ Aluno do Programa de Pós-graduação em Estudos da Linguagem, em nível de Doutorado, pela Universidade Estadual de Londrina - UEL (PR) (início em 2020), mestre em Estudos da Linguagem (2013) e graduado em Letras (1999), pela Universidade Estadual de Londrina (UEL). Email: marceloacri@gmail.com. ORCID: $\underline{\text { http://lattes.cnpq.br/5027395689394253 }}$
}

Revista Devir Educação, Lavras-MG. Edição Especial, p.141-160, Set./2021. 


\section{OO DEVIR EDUCAÇÃO}

ISSN: 2526-849X

meeting the demands generated in the context of remote teaching, be it during or after the pandemic period.

Keywords: Emergency remote teaching; teacher training; digital literacy, assessment literacy, active methodologies.

\section{Resumen}

La pandemia Covid-19 provocó varios cambios en el escenario educativo: la suspensión de las clases presenciales y la adopción de la enseñanza remota de emergencia puso a prueba la capacidad de adaptación al nuevo contexto y sacó a la luz importantes discusiones sobre la formación (inicial y continuada) de los profesores. A modo de ilustración, la investigación "La educación escolar en tiempos de pandemia" (FUNDAÇÃO CARLOS CHAGAS, 2020) muestra que la alfabetización digital y la alfabetización en evaluación constituyen conocimientos que ya eran imprescindibles incluso en tiempos de enseñanza presencial, y que podrían han ayudado a suavizatransición al aprendizaje remoto de emergencia. En este sentido, este artículo pretende establecer un diálogo entre los supuestos de la alfabetización digital (DUDENEY et al., 2016; HEALEY et al., 2008) y la alfabetización en evaluación (QUEVEDO-CAMARGO; SCARAMUCCI, 2018; STIGGINS, 1991) combinado con metodologías activas (BACICH, 2017; DIEHL, 2020; MITRE et al., 2008; RESER; ROCA; SILVA, 2018) en atender las demandas generadas en el contexto de la educación remota durante y después de la pandemia.

Palabras clave: Educación remota de emergencia; la formación de maestros; alfabetización digital; alfabetización en evaluación; metodologías activas.

\section{Introdução}

O ano de 2020 ficou definitivamente marcado pela pandemia do novo coronavírus SARS-CoV-19 (Covid-19). Para evitar o colapso do sistema de saúde, o distanciamento social foi adotado como a principal recomendação dos órgãos oficiais do Brasil e do mundo, impossibilitando a continuidade das aulas na modalidade presencial. Tal medida, além de evidenciar as dificuldades que o sistema educacional brasileiro já vinha enfrentando (falta de recursos e infraestrutura básica; alunos que tinham a merenda escolar como principal, ou mesmo única, fonte de alimentação diária; escolas que não dispunham de condições mínimas de higiene e saneamento básico; entre outros), trouxe outras questões que impuseram mudanças radicais nas formas de ensinar, aprender e avaliar.

Diante desse cenário, a utilização de ferramentas tecnológicas, além de metodologias capazes de atender ao contexto, têm se mostrado como importantes estratégias para amenizar alguns dos efeitos da suspensão das aulas. Assim, as Tecnologias Digitais de Informação e Comunicação (TDIC) têm sido mais do que ferramentas adicionais para ensino e 


\section{OO DEVIR EDUCAÇÃO}

ISSN: 2526-849X

aprendizagem - na verdade, têm sido a principal forma de interação entre professor e aluno -, o que provoca alterações marcantes no lugar que a tecnologia vinha ocupando no ensino. Por esse motivo, consideramos que alguns conceitos precisam ser tratados e é importante que ressignifiquemos o papel que as TDIC têm, sobretudo, na avaliação da aprendizagem do aluno no ensino remoto durante e pós-pandemia.

Lévy (1996, p. 17) trata do conceito de virtualização e a caracteriza como

uma mutação de identidade, um deslocamento do centro de gravidade ontológico do objeto considerado: em vez de se definir principalmente por sua atualidade (uma "solução"), a entidade passa a encontrar sua consistência essencial num campo problemático.

Podemos transpor esse conceito para nosso contexto ao compreendermos que a escola virtualizou-se, ou seja, as suas coordenadas espaciais e temporais de trabalho tornaram-se um problema que deve ser constantemente repensado. O "centro de gravidade" da escola (no caso) "não é mais um conjunto de" salas, ambientes, setores e departamentos, assim como de espaços e momentos de planejamento, organização, ação e avaliação, "mas um processo de coordenação que redistribui sempre diferentemente as coordenadas espaço-temporais da coletividade de trabalho e de cada um de seus membros em função de diversas exigências." (LÉVY, 1996, p. 18).

Não ignoramos a importância dos fatores de natureza política, econômica, social, estrutural, psicológica e emocional que impactam o sistema educacional neste momento. No entanto, o fenômeno de virtualização da escola, intensificado pela situação de pandemia, nos chama atenção para o problema da carência de cursos de formação docente (inicial e continuada) com foco no letramento digital e no letramento em avaliação. A nosso ver, essa falta de práticas alicerçadas em aportes teórico-metodológicos sólidos veio a dificultar, em grande medida, a transição do ensino presencial para o contexto remoto.

O Ensino a Distância (EaD) já estava previsto como modalidade educacional no art. 80 da Lei no 9.394/1996 - LDB (BRASIL, 1996), que estabeleceu as diretrizes e bases da educação nacional há 24 anos. Embora o uso pedagógico de TDIC já se fizesse presente na realidade pré-pandemia, inclusive sendo enfatizado em documentos oficiais como a Base Nacional Comum Curricular (BNCC) e as Orientações Curriculares para o Ensino Médio (OCEM), o estudo de Marzari e Leffa (2013, p. 5) aponta que a "situação dos cursos de formação de professores tem demonstrado uma realidade ainda distante do que se considera ideal em se tratando das tecnologias digitais e suas implicações para o ensino". O fato de que

Revista Devir Educação, Lavras-MG. Edição Especial, p.141-160, Set./2021. 


\section{OO DEVIR EDUCAÇÃO}

ISSN: 2526-849X

o letramento digital é ainda matéria incipiente entre professores, além de promover o descompasso entre estes e seus alunos pertencentes à geração chamada de nativos digitais ${ }^{3}$, veio a acentuar as dificuldades de planejamento e adequação das atividades pedagógicas para o contexto on-line.

Dentro desse panorama, a avaliação (que, apesar de costumeiramente ser pensada no final do processo de ensino e aprendizagem e ser pouco compreendida, é - ou deveria ser definidora e orientadora de todas as ações do professor em busca do ensino e da aprendizagem), agora sofre duras penas. Como garantir que haja aprendizado e como verificálo em um momento como esse, em que escola, professores e alunos têm vivenciado tantos empecilhos para continuar ensinando e aprendendo? Evidencia-se, na prática, que o nível de letramento em avaliação no Brasil está longe de ser considerado satisfatório "quando consideramos os diversos papéis que a avaliação desempenha na sociedade e as demandas diferenciadas em cada uma dessas atuações" (SCARAMUCCI, 2016, p. 152).

Em tempos de não distanciamento social, o espaço da escola define o tempo da escola. Entretanto, percebemos que a adoção do ensino remoto provocou a emergência de funções e ações não esperadas pelos professores. Contrariando o senso comum de que a internet desconstrói (somente) o espaço, percebeu-se que, além dele, o tempo e as atribuições também foram desconstruídos, ampliados em uma magnitude que tem dificultado o papel do professor, sobretudo no que se refere à avaliação. Este fator reforça a necessidade de repensarmos o processo, a partir do planejamento de ações sistematizadas, com foco no médio-longo prazo e que tenham em vista a busca por formação contínua, caracterizando o que Ayrosa (2020) denomina por uma transição do ensino remoto emergencial (de improviso), para o ensino remoto intencional.

Percebemos que, nos últimos anos, cursos e encontros de formação têm focado a BNCC e as mudanças que ela tem provocado. Reconhecemos a importância do tema, no entanto, o contexto pandêmico colocou à prova a capacidade de todo o sistema educacional se adaptar à nova situação e ressaltou a importância de se ampliar o escopo das ações de

\footnotetext{
${ }^{3}$ Segundo Prensky (2001), a expressão "nativos digitais" refere-se às gerações que já nasceram em meio à tecnologia e, portanto, são "falantes nativos" da linguagem digital de computadores, vídeo games e internet. Contudo, concordamos com Azevedo e colaboradores, $(2018$, p. 620) ao afirmarem que: "É preciso mais do que ter nascido e crescido em contato com os artefatos tecnológicos. O uso consciente das tecnologias deve ser ensinado e aprendido, como qualquer outra habilidade cognitiva".
} 


\section{OO DEVIR EDUCAÇÃO}

ISSN: 2526-849X

formação (inicial e continuada) de professores, incorporando tópicos como letramento digital, letramento em avaliação e metodologias que se distanciem da educação bancária.

Em vista do exposto, neste artigo objetivamos alinhar premissas do letramento digital (DUDENEY et al., 2016; HEALEY et al., 2008) e do letramento em avaliação (QUEVEDOCAMARGO; SCARAMUCCI, 2018; STIGGINS, 1991) combinados ao uso das TDIC e de metodologias ativas (BACICH, 2017; DIEHL, 2020; MITRE et al., 2008; RESER et al., 2018) no atendimento às demandas geradas em contexto pandêmico e pós-pandêmico.

Nesse sentido, partindo de dados extraídos da pesquisa "Educação escolar em tempos de pandemia" (FUNDAÇÃO CARLOS CHAGAS, 2020), realizada no período entre 30 de abril a 10 de maio de 2020, pelo Departamento de Pesquisas Educacionais da Fundação Carlos Chagas, em parceria com a UNESCO do Brasil e com o Itaú Social, e de respostas a um questionário ${ }^{4}$ por nós proposto a colegas professores, intentamos alinhavar a discussão aos pressupostos teóricos acima elencados a fim de tecermos algumas considerações que podem contribuir para futuros encaminhamentos.

\section{Um novo contexto e suas (não tão) novas necessidades}

\section{Letramento digital}

Propomos começar nossa reflexão remetendo ao início da suspensão das aulas presenciais e à iminente necessidade de adaptação do tempo e do espaço das aulas. De modo geral, a confusão entre os conceitos de $\mathrm{EaD}$ e ensino remoto pairou sobre a sociedade acarretando reações negativas à adoção do ensino remoto. Com base em argumentos alheios à realidade imposta pela pandemia, houve quem se recusasse ou criasse resistência ao uso de TDIC como forma de dar continuidade às atividades escolares e acadêmicas.

É preciso elucidar: ensino remoto não se confunde com EaD. Ayrosa (2020) explica que o $\mathrm{EaD}$ se trata de uma modalidade de ensino prevista na LDB e regulamentada pelo Decreto 9.057/2017 (BRASIL, 2017). É estruturada segundo aspectos institucionais, pedagógicos, tecnológicos e organizacionais, com vistas a atender grande número de alunos

\footnotetext{
${ }^{4}$ Trata-se de questionário online composto por 13 perguntas que fez parte de trabalho sobre instrumentos e critérios de avaliação, desenvolvido e apresentado em junho de 2020 para a disciplina de Avaliação no Ensino e na Aprendizagem de Línguas, do Programa de Pós-Graduação em Estudos da Linguagem, da Universidade Estadual de Londrina. Dentre os 17 colegas da turma, contamos com 12 respondentes, os quais autorizaram a utilização dos registros neste artigo.
}

Revista Devir Educação, Lavras-MG. Edição Especial, p.141-160, Set./2021. 


\section{OO DEVIR EDUCAÇÃO}

ISSN: 2526-849X

local ou mesmo internacionalmente. Portanto, o professor não desenvolve o trabalho sozinho, mas junto a uma equipe previamente capacitada e com infraestrutura apropriada para tal finalidade.

Ainda na conceituação de Ayrosa (2020), ensino remoto, por sua vez, é uma das metodologias de ensino híbrido que se situam entre os extremos do ensino presencial e do $\mathrm{EaD}$. No contexto pandêmico, o ensino remoto foi adotado temporariamente, em um modelo que, na maioria das vezes, o professor atua sozinho planejando, adaptando e disponibilizando suas aulas e materiais a seus grupos de alunos. De início, não houve tempo para se fazer um planejamento sistemático nem capacitação prévia, tampouco puderam ser fornecidas condições técnicas de acesso universal aos alunos. A condução dos trabalhos foi, em geral, feita com a perspectiva de curto prazo, esperando-se o retorno à modalidade presencial o mais brevemente possível.

Assim sendo, o ensino remoto não constitui uma tentativa de se transformar o ensino presencial em EaD, como muitos chegaram a alegar. Concordamos com Oliveira e Souza (2020, p. 22) quando afirmam que "a necessidade de se reinventar é premente em tempos de crise". Não desconsideramos o fato de que a adoção do ensino remoto ampliou as lacunas e das desigualdades sociais. No entanto, o uso de TDIC constituiu elemento que, necessariamente, integrou esse processo de reinvenção e foi uma das poucas alternativas viáveis na continuidade das atividades escolares/ acadêmicas.

A pesquisa "Educação escolar em tempos de pandemia" ilustra bem o panorama nacional e serve de pano de fundo para importantes reflexões. Com a participação de 14.285 professores de todo o território nacional, a pesquisa revelou que o uso de ferramentas tecnológicas assumiu destaque entre as estratégias adotadas no processo ensinoaprendizagem, na capacitação docente e nas interações com a equipe pedagógica e com as famílias dos alunos. Quase oito em cada dez professores afirmaram incluir em suas estratégias educacionais materiais digitais e redes sociais e "para mais de $65 \%$ das respondentes, o trabalho pedagógico mudou e aumentou, com destaque para as atividades que envolvem interface e/ou interação digital" (FUNDAÇÃO CARLOS CHAGAS, 2020, p. 2).

Contudo, corroboramos o pensamento de Marzari e Leffa (2013, p. 3), ao afirmar que "formar um professor para atuar na sociedade contemporânea, ou pós-moderna, parece ser uma tarefa ainda mais complexa, principalmente diante da diversidade de instrumentos de 


\section{OO DEVIR EDUCAÇÃO}

ISSN: 2526-849X

mediação didático-pedagógica que estão hoje à nossa disposição", e entendemos que a pandemia veio a acelerar o processo de integração das TDIC às práticas pedagógicas.

De acordo com Dudeney et al. (2016), o letramento digital abarca habilidades individuais e sociais exigidas para interpretação, administração, compartilhamento e criação de sentido por meios do uso de TDIC. Por isso, entendemos que apenas o uso instrumental de ferramentas tecnológicas, enquanto suporte para a aula, caracteriza uma prática de letramento digital em um nível básico e superficial, sobretudo quando levamos em consideração que o letramento digital comporta multiletramentos e ancora-se em mais de um foco (linguagem, informação, conexão e design) (HEALEY et al., 2008). Em outras palavras, não se pode dizer que transpor o conteúdo da lousa para um aplicativo de apresentação de slides seja um exemplo de uso inovador da tecnologia. O uso de TDIC deve possibilitar, além do acesso, a construção do conhecimento, levando em conta os objetivos de aprendizagem e contemplando as reais necessidades dos alunos.

Assim, reafirmamos os postulados de Marzari e Leffa (2013, p. 4), ao dizer que é urgente que seja proporcionada formação em letramento digital, não apenas para apresentar ferramentas digitais aos professores, mas principalmente para que se apropriem desses recursos tecnológicos, "utilizando-os de forma coerente, reflexiva e criativa" e para que ensinem a seus alunos "novas práticas de leitura e escrita, decorrentes da substituição do papel (texto impresso) pela tela (texto digital)".

\section{Letramento em avaliação}

Em seu relatório $n^{\circ}$. 2, "Educação escolar em tempos de pandemia" afirma que diversas estratégias foram utilizadas para disponibilizar os conteúdos das disciplinas aos estudantes: desde materiais digitais via rede social, a aulas ao vivo (on-line) e gravadas, a fim de manter um modelo mais próximo da rotina presencial. Entretanto, a adoção do ensino remoto emergencial se deu, em boa parte dos contextos, de forma conturbada e sem o devido preparo, tanto em termos de capacitação, quanto em termos de recursos necessários ao acesso às plataformas digitais.

Dados preocupantes sobre os efeitos da suspensão das aulas presenciais para os alunos são apontados desde o primeiro relatório da pesquisa: na percepção de 49,7\% dos professores respondentes, a aprendizagem de seus alunos diminuiu, ainda que os alunos estejam 


\section{OO DEVIR EDUCAÇÃO}

ISSN: 2526-849X

realizando as tarefas propostas. Considerando o retorno às aulas presenciais, 84,6\% concordam que haja necessidade de readequação dos modelos de avaliação.

De fato, a situação imposta pela pandemia exige, de um lado, repensar os conteúdos e as práticas pedagógicas adaptadas para um contexto virtual e, de outro, requer discutir atividades avaliativas considerando a diversidade de situações e condições de vida em que se encontram os estudantes dos diversos níveis de ensino. Não se trata, apenas, de transpor práticas que antes eram feitas presencialmente para contextos virtuais (FUNDAÇÃO CARLOS CHAGAS, 2020, p. 3).

Nossa maior preocupação é com as formas pelas quais se daria tal readequação. Considerando-se que o cumprimento das atividades pela maior parte dos alunos, aparentemente, não está sendo percebido como suficiente para garantir bons níveis de aprendizagem, seria necessário avaliá-los a partir de formas e critérios menos exigentes que o usual? Embora a pesquisa tenha se referido à readequação da avaliação a ser feita após o retorno às aulas presenciais, como fica a avaliação formativa, que deveria ocorrer durante o processo?

Respostas a um questionário que aplicamos a colegas professores, em junho de 2020, reforçam nossas preocupações relacionadas à avaliação no contexto de ensino remoto e no pós-pandemia. Para 75\% dos respondentes, a pandemia e as aulas remotas acarretaram mudanças nas formas de ensinar e avaliar. Houve relatos de intensificação da utilização de ferramentas tecnológicas, como realização de provas escritas adaptadas ao Google Forms, solicitação de envio de tarefas escritas e áudios via WhatsApp e uso de questionários interativos. De modo geral, percebemos que houve diversificação dos instrumentos utilizados para avaliar, incluindo atividades com gêneros textuais diversos, relatórios e estudos de caso.

Entretanto, as respostas demonstram que o cenário parece demandar atenção no que se refere aos critérios empregados na avaliação. Houve comentários sobre situações em que os colegas professores, por mais que se dedicassem ao planejamento de atividades que contemplassem a avaliação formativa, acabaram esbarrando em opiniões contrárias, tanto de seus pares, como de seus coordenadores pedagógicos. Estes consideram que o momento justifica certo abandono dos critérios de avaliação e redução no grau de exigência/ dificuldade das tarefas propostas aos alunos, o que leva a crer que esteja havendo confusão entre flexibilização de critérios (negociá-los e estabelecê-los, a partir de diálogo franco entre professor e alunos) e o relaxamento destes.

Revista Devir Educação, Lavras-MG. Edição Especial, p.141-160, Set./2021. 


\section{OO DEVIR EDUCAÇÃO}

ISSN: 2526-849X

Os relatos de simplificação de feedbacks, flexibilização de critérios, avaliação restrita à verificação de retenção de conteúdo e se a tarefa foi feita "de forma satisfatória", bem como o sentimento de angústia dos colegas participantes vêm a reafirmar nossa preocupação com a avaliação em tempos de ensino remoto, pois

O questionamento acerca do processo avaliativo dos estudantes frente à pandemia do coronavírus merece uma atenção redobrada, uma vez que por meio da avaliação - geralmente, no método tradicional, direcionada apenas ao instrumento avaliativo chamado de prova - o professor pode chegar à conclusão de que o estudante aprendeu, ou não, os conteúdos que foram discutidos "em sala de aula" - pelo método tradicional, repassados - e, a partir daí, considerá-lo, ou não, aprovado (OLIVEIRA; SOUZA, 2020, p. 20).

Tendo como perspectiva a avaliação formativa, as tecnologias digitais podem ser de grande valia, porém, sabemos que não podem ser esquecidas as etapas iniciais do planejamento do trabalho do professor. Após elencar os conteúdos e habilidades, evidenciar os objetivos de aprendizagem e planejar as atividades, Bacich e Moran (2018, p. 136) elucidam que é preciso organizar como as TDIC poderão "tornar essa etapa mais rápida e eficiente" para professor e alunos, sempre de forma que os professores possam compreender em que níveis estão desenvolvidos o conhecimento e as habilidades dos alunos, assim como "seus estilos preferidos de aprendizagem, comportamentos típicos em sala de aula, interesses e desinteresses e relações de trabalho com seus colegas".

Salientamos, portanto, que o uso pedagógico de TDIC deve somar-se ao aprofundamento em letramento em avaliação. Segundo Fulcher (2012, p. 125), o letramento em avaliação compreende

"Conhecimentos, habilidades e capacidades exigidos para que seja possível elaborar e realizar avaliações na sala de aula ou em uma escala mais abrangente, assim como a compreensão mais profunda de processos de avaliação, seus princípios e conceitos, incluindo questões éticas e procedimentais. Além disso, esse letramento também envolve o conhecimento histórico, social, político e filosófico de práticas avaliativas, compreendendo sua evolução e impactos sociais, institucionais e individuais." 5

\footnotetext{
${ }^{5}$ Do original: "The knowledge, skills and abilities required to design, develop, maintain or evaluate, large-scale standardized and/or classroom based tests, familiarity with test processes, and awareness of principles and concepts that guide and underpin practice ethics and codes of practice. The ability to place knowledge, skills, processes, principles and concepts within wider historical, social, political and philosophical frameworks in order understand why practices have arisen as they have, and to evaluate the role and impact of testing on society, institutions, and individuals". Tradução nossa.
} 


\section{OO DEVIR EDUCAÇÃO}

ISSN: 2526-849X

Nesse aspecto, aquele que é letrado em avaliação tem (no mínimo) um bom conhecimento do processo de ensino e aprendizagem e do papel que a avaliação desempenha antes, durante e depois, assim como dos instrumentos de avaliação e aspectos que os caracterizam, tais como confiabilidade, validade, autenticidade e efeito retroativo ${ }^{6}$.

Segundo Quevedo-Camargo e Scaramucci (2018, p. 230), ser letrado em avaliação equivale a compreender "toda a gama dos possíveis objetivos de rendimento a serem atingidos pelos alunos e os métodos de avaliação à disposição no contexto educacional”. O professor letrado em avaliação deve ter

[...] uma compreensão básica do que é uma avaliação de alta e baixa qualidade e ser capaz de aplicar esse conhecimento a várias mensurações do rendimento do aluno. Aqueles que são letrados em avaliação fazem duas perguntas-chave sobre todas as avaliações do rendimento do aluno: $\mathrm{O}$ que essa avaliação diz aos alunos sobre os resultados de rendimento que valorizamos? E qual é o provável efeito dessa avaliação nos alunos? Os letrados em avaliação buscam e usam avaliações que transmitem definições ricas, específicas e claras do rendimento que é valorizado (STIGGINS, 1991, p. 535).

Haydt (2011, p. 287) afirma que a avaliação, atualmente, “assume novas funções, pois é um meio de diagnosticar e de verificar em que medida os objetivos propostos para o processo ensino-aprendizagem estão sendo atingidos". Dessa forma, a avaliação atende a alguns pressupostos e princípios importantes: é um processo contínuo e sistemático, é funcional e tem objetivos previstos, é orientadora ao indicar avanços e dificuldades dos avaliados e é holística, por considerar o aluno como um sujeito integral.

Sobre as funções da avaliação, a autora as relaciona aos propósitos aos quais a avaliação servirá em determinado momento.

\begin{tabular}{|l|c|l|}
\hline \multicolumn{1}{|c|}{ A avaliação servirá para... } & Função da avaliação & \multicolumn{1}{c|}{ Período } \\
\hline $\begin{array}{l}\text { - Conhecer os alunos; } \\
\text { - Verificar conhecimentos prévios; } \\
\text { - Identificar dificuldades de } \\
\text { aprendizagem; }\end{array}$ & Diagnóstica & $\begin{array}{l}\text { Início do período letivo ou } \\
\text { - Auxilias de começar uma } \\
\text { unidade de ensino. }\end{array}$ \\
conhecimentos e habiliçãado de & & \\
\hline
\end{tabular}

${ }^{6}$ Sobre esses aspectos, sugerimos leitura de SCHLATTER, Margarete; et. al. Avaliação de desempenho e os conceitos de validade, confiabilidade e efeito retroativo. In: NASCIMENTO, Valdir Flores do; NAUJORKS, Jane da Costa; REBELLO, L. S. et al. (Orgs.). A redação no contexto do vestibular 2005: a avaliação em perspectiva. Porto Alegre: UFRGS, 2005.

Revista Devir Educação, Lavras-MG. Edição Especial, p.141-160, Set./2021. 


\section{OO DEVIR EDUCAÇÃO}

ISSN: 2526-849X

\begin{tabular}{|l|l|l|}
$\begin{array}{l}\text { devem ser retomados antes de se } \\
\text { introduzir novos conteúdos. }\end{array}$ & \\
\hline $\begin{array}{l}\text { - Determinar se os objetivos } \\
\text { propostos foram ou não atingidos; } \\
\text { - Verificar onde é preciso } \\
\text { readequar procedimentos de } \\
\text { ensino às necessidades dos alunos; } \\
\text { - Fornecer aos alunos feedback } \\
\text { sobre seus avanços e dificuldades, } \\
\text { de modo que possam superá-las; } \\
\text { - Aperfeiçoar o processo ensino- } \\
\text { aprendizagem. }\end{array}$ & Formativa & Durante todo o período. \\
\hline $\begin{array}{l}\text { - Promover os alunos para a } \\
\text { próxima etapa; } \\
\text { - Classificar os alunos de acordo } \\
\text { com os níveis de aproveitamento } \\
\text { atingidos. }\end{array}$ & Somativa & $\begin{array}{l}\text { Ao final do período ou de } \\
\text { pontos específicos } \\
\text { (metade da unidade } \\
\text { didática, por exemplo). }\end{array}$ \\
\hline \multicolumn{1}{|c|}{ Quadro 1: Funções da avaliação } \\
\end{tabular}

No tocante a técnicas e instrumentos de avaliação, Furtoso (2011) elucida que as técnicas estão relacionadas às formas de se avaliar, de se obter informações sobre a aprendizagem dos alunos. Elas correspondem a ações (observar, inquirir, testar, solicitar que se autoavaliem, por exemplo). Os instrumentos de avaliação, por sua vez, correspondem aos meios pelos quais serão coletadas essas informações. São exemplos de instrumentos de avaliação, além da prova tradicional: produção de texto, questionário, dramatização, trabalho de pesquisa (individuais ou em grupo), apresentação oral, experimentação, desenho, maquete, portfólio, debate, brainstorm, relatório, resumo, diários, entrevistas, projetos, quizzes, etc.

Quanto mais técnicas e instrumentos o professor utilizar, maior será a quantidade e variedade de informações que ele terá, tanto para reconduzir seu trabalho, de acordo com as necessidades da turma, como para orientar a aprendizagem dos alunos (HAYDT, 2011).

Assim, importa ao professor ter em mente "saber por quê, o quê, quando e como avaliar seus alunos, assim como deve saber interpretar os resultados obtidos por meio de suas avaliações” (QUEVEDO-CAMARGO; SCARAMUCCI, 2018, p. 239). Partindo dessas questões, apoiamo-nos em leituras de Furtoso (2011) e Haydt (2011) e esquematizamos perguntas (Figura 1) que podem ajudar no planejamento da avaliação, no que tange a instrumentos e critérios.

Revista Devir Educação, Lavras-MG. Edição Especial, p.141-160, Set./2021. 


\section{OO DEVIR EDUCAÇÃO}

ISSN: 2526-849X
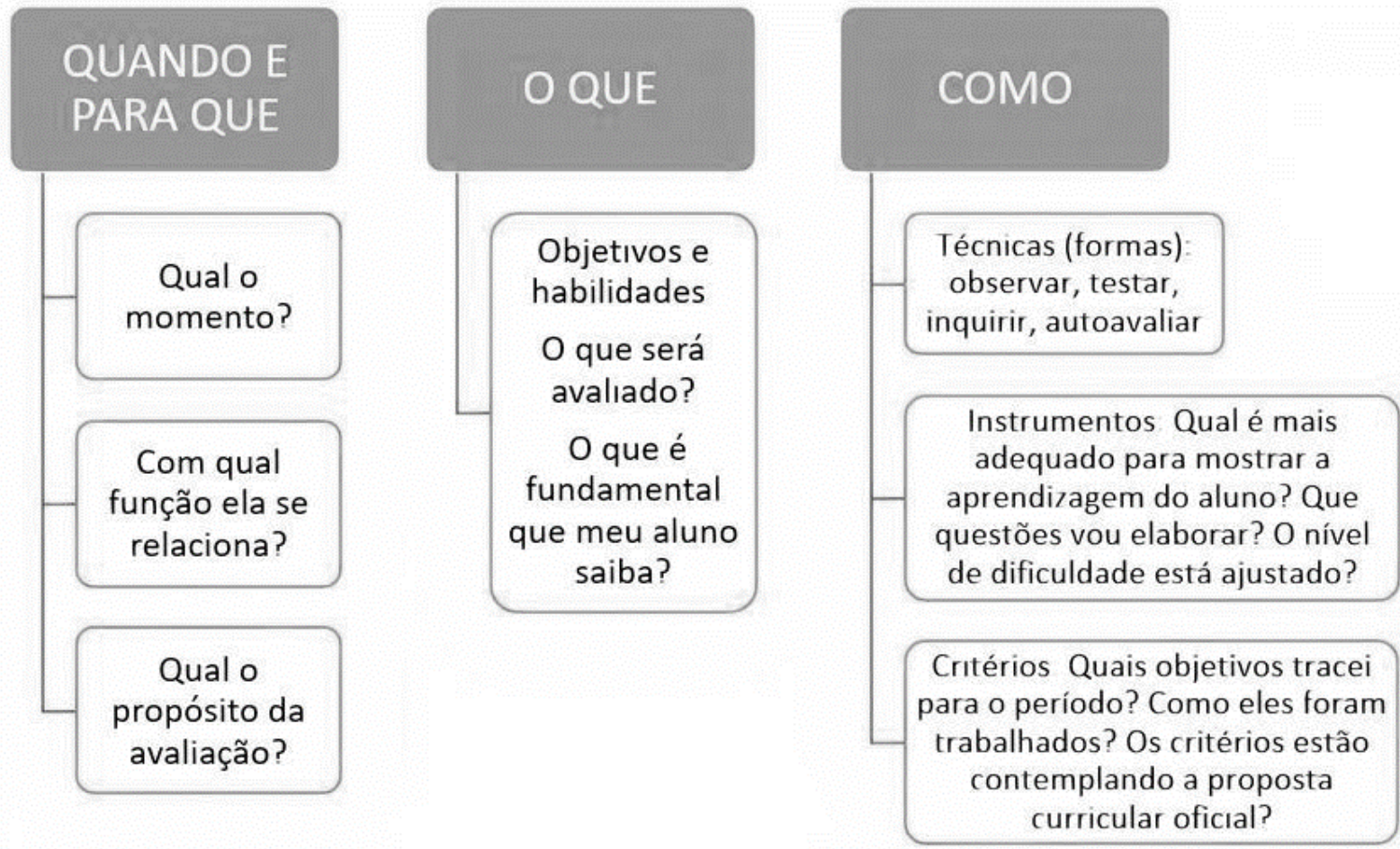

Figura 1: Questões centrais ao planejamento da avaliação Fonte: Dos autores (2020).

Enfatizamos que os critérios se relacionam com os objetivos de aprendizagem e, portanto, precisam ser compartilhados com os alunos, para que eles saibam o que se espera deles e consigam direcionar sua aprendizagem. Além disso, avaliar com base em critérios minimiza a possibilidade de limitar a avaliação ao julgamento com base em impressões, preconceitos e comparações entre alunos, além de conferir transparência ao processo de avaliação, fazendo crescer o senso de justiça.

Stiggins (1991) informa que o letramento em avaliação abarca aspectos relacionados a toda a comunidade escolar (resguardando-se as proporções e níveis de complexidade). $\mathrm{O}$ papel do professor se estende a: estar aberto a reorientar suas próprias práticas e formas de avaliar; ensinar os alunos a receber criticamente o feedback sobre seu desempenho e a defender seus pontos de vista no que tange à avaliação; orientar os pais e responsáveis a interpretarem as notas de seus filhos. Para o autor, aprimorar o letramento em avaliação envolve, necessariamente, que esses atores sociais compartilhem e ampliem a demanda por esse tipo de conhecimento.

Por conseguinte, percebe-se a necessidade da oferta de cursos de formação (inicial e continuada) para a promoção de letramento em avaliação, "se quisermos construir uma 


\section{OO DEVIR EDUCAÇÃO}

ISSN: 2526-849X

comunidade de boas práticas, preocupada com equidade e ciente dos impactos que a avaliação tem como uma prática social" (SCARAMUCCI, 2016, p. 158).

Para que a formação do professor possa fazer uma diferença e levar a uma avaliação significativa e "transformadora", entretanto, teria que incluir competências desenvolvidas a partir da reflexão e teorização sobre práticas situadas, informadas por conhecimentos teóricos e a partir das crenças dos professores e da cultura local (SCARAMUCCI, 2016, p. 155).

Se por um lado a suspensão das aulas presenciais escancarou dificuldades e carências de toda ordem, por outro, pode constituir oportunidade para agir. Imaginar que há pouco conhecimento dos professores em relação ao uso pedagógico de TDIC e ao ato de avaliar, além da escassez de treinamentos e cursos para sanar essa situação, a nosso ver, demonstra o longo caminho a ser trilhado pelas políticas educacionais brasileiras.

\section{Metodologias ativas}

As possibilidades pedagógicas que se abrem por meio do uso de TDIC implicam, também, em mudanças metodológicas. Reser, Rocha e Silva (2018) advogam que as mudanças sociais, científicas e tecnológicas, por si mesmas, geram a necessidade de reformulação do processo educativo, em que sejam estimuladas a autonomia, a responsabilidade, a reflexão crítica, o diálogo, o respeito e a ressignificação. Os autores apresentam metodologias ativas como aquelas que "propõem que o indivíduo seja colocado no centro do processo de ensino-aprendizagem, estimulando-o e transformando-o no principal agente de seu desenvolvimento crítico e reflexivo" (RESER; ROCHA; SILVA, 2018, p. 91).

Para Bacich (2017, p. 1) metodologias ativas são aquelas que

Valorizam a participação efetiva dos alunos na construção do conhecimento e no desenvolvimento de competências, possibilitando que aprendam em seu próprio ritmo, tempo e estilo, por meio de diferentes formas de experimentação e compartilhamento, dentro e fora da sala de aula, com mediação de docentes inspiradores e incorporação de todas as possibilidades do mundo digital.

Diehl (2020) complementa ao dizer que as metodologias ativas se utilizam da diversificação de ferramentas de ensino, reforçam a socialização e a interação com os pares e com o professor na construção do conhecimento e mesclam metodologias, sejam estas presenciais ou não. Essa concepção vem ao encontro da visão de Reser, Rocha e Silva (2018), em que a avaliação assume caráter autoavaliativo, colaborativo, planejado, dinâmico e 


\section{OO DEVIR EDUCAÇÃO}

ISSN: 2526-849X

estimulante, considerando a diversidade dos sujeitos, desde seus interesses, dificuldades e ritmos de aprendizagem.

Para Mitre e colaboradores (2008), as metodologias ativas incluem como instrumentos pedagógicos a problematização, estudos de casos, aprendizagem em pares ou times, sala de aula invertida, entre outros. A avaliação não se restringe à verificação de conteúdos com finalidade somativa, mas deve assumir caráter formativo, baseado na colaboração, no empenho, no constante fornecimento de feedbacks.

Os registros, a autoavaliação e o diálogo têm sido utilizados como estratégias norteadoras desse processo. $\mathrm{O}$ docente pode registrar o desenvolvimento do discente no que se refere à autonomia, à criatividade, à capacidade de organização, à sua participação e a condições de elaboração, bem como ao seu relacionamento com o grupo e sua comunicação (MITRE et al., 2008, p. 2138).

Moraes (2020) defende que as atividades de avaliação em contexto virtual devem priorizar a função formativa e estar integradas com o processo pedagógico, priorizando o trabalho de conteúdos essenciais por meio de análise, síntese, discussão e resolução de problemas. Ela sugere a diversificação das estratégias e o desenvolvimento de comunidades de aprendizagem, em que sejam estimulados aspectos como participação colaborativa, interação, confronto cognitivo, negociação e diálogo.

Tanto Moraes (2020) quanto Diehl (2020) dão exemplos de ferramentas tecnológicas que podem ser utilizadas para propor metodologias ativas no ensino remoto, as quais sintetizamos no quadro 1.

\begin{tabular}{|l|l|}
\hline \multicolumn{1}{|c|}{ Atividades / instrumentos de avaliação } & \multicolumn{1}{|c|}{ Ferramentas tecnológicas } \\
\hline $\begin{array}{l}\text { Atividades programadas pelo professor em } \\
\text { ambientes virtuais de aprendizagem }\end{array}$ & $\begin{array}{l}\text { Moodle } \\
\text { Google Classroom } \\
\text { Google Forms }\end{array}$ \\
\hline Ferramentas de interação & $\begin{array}{l}\text { Mentimeter } \\
\text { Poll Everywhere } \\
\text { Enquetes do Zoom }\end{array}$ \\
\hline $\begin{array}{l}\text { Projetos colaborativos (banco de dados, } \\
\text { glossário, blogs, sites, portfólios, e-books, } \\
\text { etc.) }\end{array}$ & $\begin{array}{l}\text { Google Docs } \\
\text { Padlet } \\
\text { Jamboard } \\
\text { Canva } \\
\text { Blogger } \\
\text { Wix }\end{array}$ \\
\hline
\end{tabular}

Revista Devir Educação, Lavras-MG. Edição Especial, p.141-160, Set./2021. 


\section{OO DEVIR EDUCAÇÃO}

ISSN: 2526-849X

\begin{tabular}{|c|c|}
\hline & $\begin{array}{l}\text { PortfolioGen } \\
\text { Book Creator } \\
\text { Instagram } \\
\text { Facebook }\end{array}$ \\
\hline Atividades competitivas (testes e questões) & $\begin{array}{l}\text { Kahoot } \\
\text { Socrative } \\
\text { Quizlet } \\
\text { Quizziz }\end{array}$ \\
\hline Fóruns & $\begin{array}{l}\text { Moodle } \\
\text { Google Classroom } \\
\text { Facebook } \\
\text { WhatsApp }\end{array}$ \\
\hline Provas online & $\begin{array}{l}\text { Prova Fácil } \\
\text { Google Forms }\end{array}$ \\
\hline $\begin{array}{l}\text { Desenvolvimento de conteúdos } \\
\text { multimodais (vídeos, animações, podcasts, } \\
\text { infográficos, apresentações, mapas } \\
\text { conceituais, etc.) }\end{array}$ & $\begin{array}{l}\text { Filmora } \\
\text { Softonic } \\
\text { Animaker } \\
\text { Audacity } \\
\text { Canva } \\
\text { Google Presentation } \\
\text { Lucidchart } \\
\text { Draw.io } \\
\text { Coggle }\end{array}$ \\
\hline $\begin{array}{l}\text { Sala de aula invertida (reuniões em } \\
\text { videoconferência) }\end{array}$ & $\begin{array}{l}\text { Zoom } \\
\text { Google Meet }\end{array}$ \\
\hline
\end{tabular}

Quadro 2: Possibilidades de avaliação mediada por ferramentas tecnológicas.

Fonte: Adaptado de Moraes (2020) e Diehl (2020).

A reconfiguração do tempo e do espaço da aula impôs novos contornos às atividades relacionadas ao ensinar e ao aprender. Salienta-se a ampliação e a complexidade do papel do professor, que não é só o de transmitir informações de determinada área, mas de arquitetar "roteiros personalizados e grupais de aprendizagem" e orientar "projetos profissionais e de vida dos alunos" (BACICH; MORAN, 2018, p. 21). Entendemos esse fato como suficiente para que se tomem ações no sentido de promover formação (inicial e continuada) que contemple preceitos do letramento digital e do letramento em avaliação aliados a metodologias que possibilitem o trabalho para além dos limites da sala de aula.

\section{Algumas considerações}

Revista Devir Educação, Lavras-MG. Edição Especial, p.141-160, Set./2021. 


\section{OO DEVIR EDUCAÇÃO}

ISSN: 2526-849X

O cenário atípico ocasionado pela pandemia da Covid-19 marcou, definitivamente, o cotidiano das escolas. Como já dissemos, a escola saiu de contextos conhecidos (o ensino tradicional coexistindo com o ensino híbrido, em uma caminhada ainda no início rumo à educação do século XXI) para um contexto totalmente novo. Professores e alunos que apenas ouviam falar na inserção de tecnologias digitais nas aulas ou que já experimentavam trazer as TDIC para suas aulas, repentinamente, tiveram de viver uma escola completamente virtualizada. A situação tornou-se ainda mais crítica com o fato de poucos professores terem tido, em sua formação, o contato com concepções de avaliação enquanto integradora do processo ensino-aprendizagem e a oportunidade de se preparar para lidar com metodologias que englobam o uso pedagógico das TDIC.

No Paraná, vimos a suspensão das aulas no mês de março e, somente quase um mês depois, os órgãos responsáveis buscarem soluções para não cancelar o ano letivo. Também vimos professores e alunos serem forçados a utilizar tecnologias com as quais poucos estavam familiarizados. O que se vê é um esforço imenso para dar continuidade ao desenvolvimento dos alunos, sem a certeza de que esteja havendo aprendizado.

Entendemos que há alguns pontos que merecem atenção em uma tentativa de se tirar lições desse período crítico pelo qual (ainda) passamos. Lições que nos permitam ampliar a visão que temos sobre o fazer pedagógico, em especial, sobre aspectos relacionados ao uso de TDIC, à avaliação e a metodologias que as interseccionam.

Tendo explicitadas as diferenças entre $\mathrm{EaD}$ e ensino remoto, resta esclarecido o fato de que as TDIC não figuram como potenciais substitutas para o professor, tampouco, constituem forma de ameaça ou depreciação do trabalho docente. A análise da pesquisa feita pela Fundação Carlos Chagas (2020) mostra que a experiência que tivemos com o ensino remoto permitiu à sociedade compreender que o ofício de ensinar vai muito além das potencialidades da máquina. Desmitificar o uso pedagógico das TDIC, a partir do investimento no letramento digital e no conhecimento acerca das possibilidades que as tecnologias digitais nos oferecem, e aliá-las a uma base teórica sólida constituem meios para transcender o tempo e o espaço da aula convencional e continuar oportunizando experiências de aprendizagem aos alunos, também, fora da sala de aula.

Deve-se considerar desenvolver o letramento em avaliação, em primeiro lugar, dos professores. Refletir sobre os instrumentos de avaliação aplicáveis nesse momento é essencial 


\section{OO DEVIR EDUCAÇÃO}

ISSN: 2526-849X

para a busca de aprendizagem efetiva. Estar em dia com os conteúdos e ter nota para aprovar alunos para satisfazer dados estatísticos não garantem a aprendizagem. Professores letrados em avaliação norteiam sua prática a partir de habilidades e conteúdos que levam ao desenvolvimento holístico dos alunos, que se percebe por instrumentos de avaliação diversificados e cuidadosamente pensados para contemplar a diversidade de habilidades, aptidões e estilos de aprendizagem, possibilitando que todos os alunos mostrem o seu melhor e tornando a avaliação um ato mais justo e humanizado.

Da mesma forma, o feedback dado para os alunos pode ser um dos aspectos mais importantes no contexto remoto. Esse retorno, além de resultar em valores numéricos para registro das notas exigidas pelo sistema, necessita ser o mais descritivo possível, a fim de que o aluno consiga ter ciência de seus avanços, dos pontos que precisam de mais atenção e dos possíveis caminhos para melhorá-los. Por meio de reuniões virtuais por vídeo, por exemplo, o professor pode realizar um feedback geral, e por meio de contatos individuais (vídeos, mensagens, e-mail, anotações na própria tarefa), é possível tratar daquilo que ainda precisa ser desenvolvido.

Existe, ainda, a necessidade de conhecer as propostas que são apresentadas por metodologias que englobam o uso das TDIC, que proporcionam diversificação de instrumentos de avaliação e que colocam o foco no processo de aprendizagem do aluno. Nesse sentido, elencamos as metodologias ativas como possibilidade viável.

Finalmente, consideramos o que traz Haydt (2011, p. 314) em relação ao ato de avaliar: "deve ser um instrumento para estimular o interesse e motivar o aluno a maior esforço e aproveitamento e não uma arma de tortura ou punição", sobretudo, em um tempo já tortuoso e difícil, em que perdas familiares e diferenças sociais e econômicas estão mais visíveis do que nunca. Precisamos resgatar o entendimento de que o processo envolve pessoas, e que todas as suas complexidades e fragilidades são trazidas para a sala de aula, seja em presença física ou virtual.

Do exposto, podemos concluir que o ensino-aprendizagem (seja remoto ou em qualquer outra modalidade ou contexto) demanda que as atividades avaliativas sejam planejadas de modo que o professor valorize o processo de desenvolvimento do trabalho dos alunos e lhes forneça feedbacks constantes para que possam ampliar suas capacidades de autonomia, autoavaliação, autorregulação e disciplina para o estudo. Nesse sentido, o letramento digital e a adoção de metodologias que englobem o uso crítico das TDIC exercem

Revista Devir Educação, Lavras-MG. Edição Especial, p.141-160, Set./2021. 


\section{OO DEVIR EDUCAÇÃO}

ISSN: 2526-849X

importante papel como instrumentos de avaliação/mediação que vão possibilitar essas aprendizagens. Para tanto, o professor (em formação ou em serviço), além de buscar se apropriar dessas tecnologias e metodologias, precisa investir em seu letramento em avaliação, a fim de compreender o papel integrador que a avaliação ocupa em todo o processo.

\section{Referências}

AYROSA, Pedro Paulo da Silva. Ensino remoto é EAD? Palestra proferida no VIRTUEL, Londrina (Paraná), jun. 2020. Disponível em: https://www.youtube.com/watch?v=kir5SKcGjw. Acesso em: 17 jun. 2020.

AZEVEDO, Daniela Simone de et al. Letramento digital: uma reflexão sobre o mito dos "nativos digitais". RENOTE, v. 16, n. 2, p. 615-625. dez. 2018. Disponível em: https://seer.ufrgs.br/renote/article/view/89222/51474. Acesso em: 27 fev. 2021.

BACICH, Lilian. Inovação na educação. Disponível em: https://lilianbacich.com/2017/11/01/metodologias-ativas-para-uma-educacao-inovadora/.

Acesso em: 29 jun. 2020.

BACICH, Lilian.; MORAN, José. Metodologias ativas para uma educação inovadora: uma abordagem teórico-prática. Porto Alegre: Penso, 2018.

BRASIL. Ministério de Educação e Cultura. LDB - Lei $\mathbf{n}^{0}$ 9.394, de 20 de dezembro de 1996. Estabelece as diretrizes e bases da Educação Nacional. Brasília: MEC, 1996. Disponível em: http://www.planalto.gov.br/ccivil_03/leis/19394.htm. Acesso em: 23 jun. 2020.

BRASIL. Decreto $\mathbf{n}^{\circ}$ 9.057, de 25 de maio de 2017. Regulamenta o art. 80 da Lei $\mathrm{n}^{\circ}$ 9.394, de 20 de dezembro de 1996, que estabelece as diretrizes e bases da educação nacional. Disponível em: http://www.planalto.gov.br/ccivil_03/_ato20152018/2017/decreto/d9057.htm. Acesso em: 23 jun. 2020.

DIEHL, Leandro Arthur. Metodologias ativas no ensino remoto. Palestra proferida no VIRTUEL, Londrina (Paraná), jun. 2020. Disponível em: https://www.youtube.com/watch?v=KDxRpF5fE4A\&t=9s. Acesso em: 29 jun. 2020.

DUDENEY, Gavin; HOCKLY, Nicky; PEGRUM, Mark. Letramentos digitais. 1. ed. São Paulo: Parábola Editorial, 2016.

FULCHER, Glenn. Assesment literacy for the language classroom. Language Assesment Quarterly, v. 9, n. 2, p. 113-132, 2012. Disponível em: http://dx.doi.org/10.1080/15434303.2011.642041. Acesso em: 12 ago. 2020.

FUNDAÇÃO CARLOS CHAGAS (Brasil). Educação escolar em tempos de pandemia. [São Paulo], 2020. Disponível em: https://www.fcc.org.br/fcc/educacao-pesquisa/educacao- 


\section{OO DEVIR EDUCAÇÃO}

ISSN: 2526-849X

escolar-em-tempos-de-pandemia-informe-n-1 e https://www.fcc.org.br/fcc/educacaopesquisa/educacao-escolar-em-tempos-de-pandemia-informe-n-2 Acesso em: 22 jun. 2020.

FURTOSO, Viviane Aparecida Bagio. Desempenho oral em português para falantes de outras línguas: da avaliação à aprendizagem de línguas estrangeiras em contexto online. 2011. Tese (Doutorado em Estudos Linguísticos) - Universidade Estadual Paulista, São José do Rio Preto, 2011. Disponível em: https://repositorio.unesp.br/handle/11449/103505. Acesso em: 19 maio 2020.

HAYDT, Regina Célia Cazaux. Avaliação do processo ensino-aprendizagem. In: HAYDT, Regina Célia C. Curso de didática geral. 1. ed. São Paulo: Ática, 2011. p. 286-319. Disponível em: https://www.academia.edu/11148299/Curso_de_Didatica_Geral__Regina_Celia_C._Haydt. Acesso em: 14 maio 2020.

HEALEY, Deborah et al. TESOL Technology Standards Framework. Alexandria, VA: TESOL, 2008. Disponível em: https://www.tesol.org/docs/defaultsource/books/bk_technologystandards_framework_721.pdf?sfvrsn=4bd0bee6_2. Acesso em: 09 dez. 2020.

LÉVY, Pierre. O que é o virtual? São Paulo: Ed. 34, 1996.

MARZARI, Gabriela; LEFFA, Vilson. O letramento digital no processo de formação de professores de línguas. Tear: Revista de Educação, Ciência e Tecnologia, Porto Alegre, v. 2, p. 1-18, dez. 2013. Disponível https://periodicos.ifrs.edu.br/index.php/tear/article/view/1816. Acesso em: 4 fev. 2021.

MITRE, Sandra Minardi et al. Metodologias ativas de ensino-aprendizagem na formação profissional em saúde: debates atuais. Ciência \& Saúde Coletiva, Rio de Janeiro, v. 13, supl. 2, p. 2133-2144, 2008. Disponível em: https://www.scielo.br/pdf/csc/v13s2/v13s2a18.pdf. Acesso em: 25 jun. 2020.

MORAES, Dirce Aparecida Foletto. Reflexões sobre a didática: planejamento e avaliação em tempos de atividades remotas. Palestra proferida no VIRTUEL, Londrina (Paraná), jun. 2020. Disponível em: https://www.youtube.com/watch?v=SAmvFtsEMVM\&t=6s. Acesso em: 26 jun. 2020.

OLIVEIRA, Hudson do Vale de; SOUZA, Francimeire Sales de. Do conteúdo programático ao sistema de avaliação: reflexões educacionais em tempos de pandemia (COVID-19). Boletim de Conjuntura, Boa Vista, v. 2, n. 5, p. 15-24, 2020. Disponível em: https://revista.ufrr.br/boca/article/view/OliveiraSouza. Acesso em: 22 jun. 2020.

PRENSKY, Marc. Digital Natives, Digital Immigrants. MCB University Press, 2001.

QUEVEDO-CAMARGO, G.; SCARAMUCCI, M. V. R. O conceito de letramento em avaliação de línguas: origem de relevância para o contexto brasileiro. Linguagem: Estudos e Pesquisas, Catalão-GO, v. 22, n. 1, p. 225-245, jan./jun. 2018. 


\section{OO DEVIR EDUCAÇÃO}

ISSN: 2526-849X

RESER, Marcelo Rodrigues; ROCHA, Cristine da; SILVA, Sabrina Lacerda da. Metodologias ativas no processo formativo em saúde. Saberes plurais: educação na saúde. Porto Alegre, v. 21, n. 3, p. 91-103, dez. 2018. Disponível em: https://seer.ufrgs.br/saberesplurais/article/view/88488. Acesso em: 22 jun. 2020.

SCARAMUCCI, Matilde Virgínia Ricardi. Letramento em avaliação (em contexto de línguas): contribuições para a linguística aplicada, educação e sociedade. In: JORDÃO, Clarissa Menezes (Org.) A linguística aplicada no Brasil: rumos e passagens. Campinas, SP: Pontes Editores, 2016. p. 141-165.

STIGGINS, Rick. Assessment Literacy. Phi Delta Kappan, v. 72, p. 534-539, 1991.

Recebido em: 29/06/21

Aprovado em 14/07/21

Revista Devir Educação, Lavras-MG. Edição Especial, p.141-160, Set./2021. 